\title{
Deposição da calda na cultura da soja em função de diferentes pressões de trabalho e pontas de pulverização ${ }^{1}$
}

\author{
João Paulo Arantes Rodrigues da Cunha ${ }^{2 *}$, Rodrigo Santos Marques ${ }^{2}$, Guilherme Sousa Alves ${ }^{2}$ \\ 10.1590/0034-737X201663060003
}

\section{RESUMO}

A pressão de trabalho influencia as características da pulverização hidráulica de produtos fitossanitários e pode alterar a penetração da calda no dossel da cultura da soja. Este trabalho teve como objetivo avaliar o efeito da pressão na deposição de calda em plantas de soja, promovida por diferentes modelos de pontas de pulverização. O experimento foi conduzido em delineamento de blocos ao acaso, em esquema fatorial $2 \times 4+1$, sendo duas pontas de pulverização (jato cônico vazio - ATR e jato cônico vazio com indução de ar - TVI) e quatro pressões de trabalho (689, 1034, 1379 e $1724 \mathrm{kPa}$ ), com um tratamento adicional (ponta de jato plano - API, a $448 \mathrm{kPa}$ ). A deposição de calda, corrigida para uma mesma taxa de aplicação (200 L ha'-1), pulverizada na cultura da soja (parte superior e inferior do cultivar Vila Rica, em estádio R6), por meio de um pulverizador de barra, foi analisada, empregando-se o traçador fluorescente Rodamina B, detectado por fluorimetria. Também foi avaliado o espectro de gotas, por meio da análise de papéis hidrossensíveis. Concluiu-se que a ponta ATR, que gerou gotas de menor tamanho e mais uniformes, propiciou maior deposição do traçador do que a ponta TVI. O aumento da pressão de trabalho acarretou diminuição da deposição nas folhas da parte inferior da planta. A deposição gerada pela ponta de jato plano (API) não diferiu das geradas pelas demais pontas avaliadas.

Palavras-chave: Glycine max L; pulverizador; tecnologia de aplicação.

\section{ABSTRACT}

\section{Spray deposition on soybean crop as a function of different service pressures and spray nozzles}

The service pressure influences the characteristics of the hydraulic spraying of pesticides and can change the spray penetration in the soybean canopy. This study aimed to evaluate the effect of pressure on the spray deposition in soybean crop, promoted by different models of spray nozzles. The experiment was conducted in a randomized block design, in a factorial model $2 \times 4+1$, with two nozzles (hollow cone - ATR and air induction hollow cone - TVI) and four service pressures $(689,1034,1379$, and $1724 \mathrm{kPa})$, with an additional treatment (flat fan nozzle at $448 \mathrm{kPa}-\mathrm{API})$. The spray deposition on soybean (top and bottom parts of Vila Rica Cultivar R6 Stage) was analyzed using the fluorescent tracer Rhodamine B detected by fluorimetry, considering the same spray volume (200 $\left.\mathrm{L} \mathrm{ha}^{-1}\right)$. We also evaluated the droplet spectrum, using the analysis of water-sensitive papers. It was concluded that the ATR nozzle, with smaller and more uniform droplets, resulted in a higher deposition of the tracer than the TVI nozzle. The pressure increase reduced deposition on the lower leaves. The deposit obtained with the flat fan nozzle (API) did not differ from those obtained by other nozzles.

Key words: Glycine max L; sprayer; application technology.

Submetido em 10/12/2014 e aprovado em 05/09/2016.

Este trabalho contou com o apoio financeiro CNPq

${ }^{2}$ Universidade Federal de Uberlândia, Instituto de Ciências Agrárias, Uberlândia, Minas Gerais, Brasil. jpcunha@iciag.ufu.br; rodrigo.agro.ufu@hotmail.com; guilhermeagro43@yahoo.com.br

*Autor para correspondência: jpcunha@iciag.ufu.br 


\section{INTRODUÇÃO}

O controle de doenças, insetos e plantas daninhas na cultura da soja (Glycine max (L.) Merrill) está diretamente ligado à tecnologia de aplicação dos produtos fitossanitários. Entre as doenças, destaca-se a ferrugem asiática, causada pelo fungo Phakopsora pachyrhizi $\mathrm{H}$. Sydow $\&$ Sydow, uma das doenças mais severas que incide na cultura, podendo causar diminuição de rendimento de até 90\%, principalmente em áreas onde o controle não é executado (Balardin et al., 2005, Godoy et al., 2009). Mesmo com a existência de moléculas de boa eficácia, a tecnologia de aplicação ainda é um fator limitante ao controle eficiente. Segundo Cunha et al. (2008), a cobertura do dossel da soja, proporcionada pela aplicação de fungicida, em geral é baixa, principalmente na parte inferior das folhas, causando controle ineficiente, que se dá pelo fato de a doença iniciar-se nas partes mais baixas da planta. Por essa razão, as aplicações precisam vencer a barreira imposta pela massa de folhas e, assim, promover boa cobertura no interior do dossel da planta (Ozkan et al., 2006).

Em relação aos insetos, destaca-se a lagarta da soja (Anticarsia gemmatalis Hubner 1818), que ocasiona grandes perdas de produtividade por desfolha (Gallo et al., 2002). A redução da área fotossintética ocorre no período larval da A. gemmatalis, que dura aproximadamente 25 dias, em que as larvas se alimentam tanto do limbo foliar quanto das nervuras, podendo chegar a uma desfolha de até $100 \%$. Neste caso, também é necessária boa cobertura das folhas pelos inseticidas.

Por essa razão, e por causa da necessidade de se incrementar a cobertura das plantas de soja com as aplicações de fitossanitários, as indústrias de pontas de pulverização têm lançado no mercado novos produtos, com intuito de melhorar a tecnologia de aplicação. Segundo Viana et al. (2009), as pontas representam componentes muito importantes em um sistema de pulverização hidráulico.

Cunha et al. (2011), no entanto, mostraram que, mesmo usando-se diferentes tipos de pontas de pulverização, permanece a dificuldade de se atingir as folhas situadas junto ao terço inferior da cultura da soja. Uma forma de se minimizar esse problema pode estar ligada à pressão de trabalho imposta pelo sistema hidráulico. O tamanho e a energia contida nas gotas são diretamente responsáveis por sua capacidade de penetração no dossel.

A influência da pressão no tamanho das gotas é bastante conhecida (Di Prinzio et al., 2010); contudo, seu efeito na deposição, não o é, visto que também existem a influência do ângulo do jato e a da energia potencial das gotas. Nuyttens et al. (2006 e 2007) mostram que a combinação ideal da ponta de pulverização com a pressão pode maximizar a eficiência de deposição do produto no alvo; não estudam, entretanto, a relação entre pressão e deposição.

Este trabalho teve como objetivo avaliar o efeito da pressão de trabalho na deposição de calda em plantas de soja, promovida por diferentes modelos de pontas de pulverização.

\section{MATERIAL E MÉTODOS}

$\mathrm{O}$ trabalho foi realizado na Fazenda Experimental Capim Branco, pertencente à Universidade Federal de Uberlândia, localizada no município de Uberlândia (Minas Gerais, Brasil), com altitude média de $872 \mathrm{~m}$. O clima da região foi classificado como Aw, pelo Sistema de Köppen. Apresenta inverno frio e seco e verão quente e chuvoso (entre os meses de outubro e março). A precipitação total anual é de 1.400 a $1.500 \mathrm{~mm}$. A temperatura média anual está entre 20 e $24^{\circ} \mathrm{C}$, variando de $18^{\circ} \mathrm{C}$, para o mês mais frio, e $25^{\circ} \mathrm{C}$, para o mês mais quente. A vegetação característica da área é o cerrado. O solo foi classificado como Latossolo Vermelho-Escuro distrófico, textura argilosa e topografia suave.

Realizou-se a semeadura direta do cultivar de soja Vila Rica, de ciclo médio, com espaçamento entre fileiras de $0,5 \mathrm{~m}$ e 11 plantas por metro linear. $\mathrm{O}$ experimento, conduzido em delineamento de blocos ao acaso, constou de nove tratamentos e quatro repetições, dispostos em esquema fatorial $2 \times 4+1$, sendo duas pontas de pulverização, quatro pressões de trabalho e um tratamento adicional (Tabela 1).

As aplicações foram feitas, simulando-se o controle da ferrugem asiática, estando a soja em estádio R6 (enchimento de grãos), com cobertura total do solo. A cultura apresentava índice de área foliar de 5,8, obtido por meio da determinação de toda a área foliar sobre a projeção de $1 \mathrm{~m}^{2}$ de solo, feita com quatro repetições.

Foi utilizado um pulverizador de arrasto, tracionado por trator 4 × 2 Ursus $(62,5 \mathrm{~kW})$, com depósito de calda de 2000 L, $18 \mathrm{~m}$ de barra e sistema de marcação de linha por espuma. A altura da barra de pulverização às plantas foi de $0,5 \mathrm{~m}$ e, a distância entre bicos, de $0,5 \mathrm{~m}$. As taxas de aplicação e as pressões de trabalho encontram-se na Tabela 1. Em todos os tratamentos, a velocidade de trabalho foi de 6 $\mathrm{km} \mathrm{h}^{-1}$. O comprimento das parcelas experimentais foi de 10 $\mathrm{m}$ e, a largura, $9 \mathrm{~m}$ (metade da barra do pulverizador). Foi deixada uma faixa de $9 \mathrm{~m}$ entre parcelas vizinhas para evitar contaminação por deriva.

A avaliação da eficiência dos tratamentos na deposição da calda pulverizada foi realizada, utilizando-se o traçador fluorescente Rodamina B (Synth, Diadema, Brasil). O corante foi utilizado junto à calda, na concentração de $50 \mathrm{~g} \mathrm{~L}^{-1}$, detectado por fluorimetria. Para tanto, foi utilizado um fluorímetro (Thermo Scientific, Modelo FM 
109515), com filtro de excitação NB 540 e filtro de emissão SC 585. Para a curva de calibração, foi empregada uma solução com concentração de $5 \mathrm{mg} \mathrm{L}^{-1}$, preparada com Rodamina B e água.

Após a pulverização, foram marcadas dez plantas, ao acaso, em cada parcela e, em cada planta, foram coletadas duas folhas: uma na parte central do terço superior (a 70 $\mathrm{cm}$ de altura) e outra na parte central do terço inferior da planta (a $30 \mathrm{~cm}$ de altura), próximas à haste principal. As folhas foram, então, agrupadas por posição na planta e colocadas em sacos plásticos, que foram fechados e acondicionados em recipientes providos de isolamento térmico e luminoso, para o transporte até o Laboratório de Mecanização Agrícola da Universidade Federal de Uberlândia (Uberlândia, Minas Gerais, Brasil). O tempo de exposição das folhas com o corante à luz solar foi sempre inferior a 15 $\min$.

A Rodamina B de cada amostra foi extraída por um volume de $100 \mathrm{~mL}$, composto pela solução de água destilada e de $0,2 \%$ de Tween 80 (polioxietilensorbitano monooleato), seguindo metodologia adaptada de Scramin et al. (2002). Após agitação por $30 \mathrm{~s}$, volumes de aproximadamente 3,0 $\mathrm{mL}$ dos extratos das amostras foram adicionados a cubetas de borossilicato, para a quantificação no fluorímetro. Todas as etapas de extração foram realizadas, protegendo-se as amostras da luz, para evitar a degradação do traçador. Estudos prévios sobre a adequação e cuidados na utilização da Rodamina B como traçador foram realizados por Alves et al. (2014).

A área das folhas foi medida, individualmente, com um medidor de área foliar (ADC BioScientific Ltda, modelo AM 300) e a soma das dez folhas de cada amostra computada para posterior uso.

Com o uso da curva de calibração, os resultados das leituras foram dados em concentração $\left(\mathrm{mg} \mathrm{L}^{-1}\right) \mathrm{e}$, de posse da concentração inicial da calda e do volume de diluição das amostras, determinou-se a massa de corante retida no alvo. Procedeu-se, então, à divisão da deposição total pela área de remoção, obtendo-se, assim, a quantidade em $\mu \mathrm{g}$ $\mathrm{cm}^{-2}$ de folha. Em vista da utilização da mesma concentra- ção do traçador, fez-se a correção matemática dos depósitos para padronizar a taxa de aplicação em $200 \mathrm{~L} \mathrm{ha}^{-1}$, permitindo a comparação entre os tratamentos, de forma similar à realizada por Ferreira et al. (2013).

Foi conduzido, de forma complementar, um estudo do espectro de gotas pulverizadas, visando a caracterizar os tratamentos, por meio da avaliação das gotas depositadas em papéis sensíveis à água (Syngenta, Basiléia, Suíça) com área de 76 × $26 \mathrm{~mm}$, seguindo-se a metodologia utilizada por Halley et al. (2008). Embora o papel sensível apresente restrições quanto à mensuração de gotas muito finas, seu uso, com a devida ressalva, fornece informações importantes para avaliar o efeito dos tratamentos na deposição de calda, mensurada a campo. Métodos de mensuração de gotas mais precisos podem ser realizados em laboratório, mas não reproduzem as condições de campo.

Antes da pulverização, foram colocados quatro papéis hidrossensíveis em cada parcela, todos suspensos em uma haste metálica imediatamente acima das plantas e mantidos na posição horizontal, com a face sensível voltada para cima. Posteriormente, foi feita a quantificação e a caracterização dos impactos em cada papel. Para isso, os papéis foram digitalizados por meio de um scanner (resolução espacial de 600 dpi não interpolados, com cores em 24 bits) e analisados, utilizando-se o programa computacional CIR 1.5 (Conteo y Tipificación de Impactos de Pulverización), específico para essa finalidade. Determinaram-se o diâmetro da mediana volumétrica (DMV ou Dv0,5), a amplitude relativa (AR) e a percentagem do volume pulverizado composto por gotas com diâmetro inferior a $100 \mu \mathrm{m}$ (Gotas < $100 \mu \mathrm{m})$.

A amplitude relativa (AR) foi determinada, utilizandose a Equação 1:

$A R=\frac{D_{v 0,9}-D_{v 0,1}}{D_{v 0,5}}$

em que:

$\mathrm{D}_{v 0,1}$ - diâmetro de gota, tal que $10 \%$ do volume do líquido pulverizado é constituído de gotas menores que esse valor, $\mu \mathrm{m}$;

Tabela 1: Descrição dos tratamentos

\begin{tabular}{lccc}
\hline Tratamento & Ponta de pulverização & Pressão $(\mathbf{k P a})$ & Taxa de aplicação $\left(\mathbf{L}\right.$ ha' $\left.{ }^{-1}\right)$ \\
\hline 1 & Jato cônico vazio - ATR Amarelo & 689 & 155 \\
2 & Jato cônico vazio - ATR Amarelo & 1034 & 193 \\
3 & Jato cônico vazio - ATR Amarelo & 1379 & 221 \\
4 & Jato cônico vazio - ATR Amarelo & 1724 & 248 \\
5 & Jato cônico vazio com indução de ar - TVI 8002 & 689 & 208 \\
6 & Jato cônico vazio com indução de ar - TVI 8002 & 1034 & 263 \\
7 & Jato cônico vazio com indução de ar - TVI 8002 & 1379 & 305 \\
8 & Jato cônico vazio com indução de ar - TVI 8002 & 1724 & 342 \\
9 & Jato plano standard - API 11002 & 448 & 180 \\
\hline
\end{tabular}


$\mathrm{D}_{v 0,5}$ - diâmetro de gota, tal que $50 \%$ do volume do líquido pulverizado é constituído de gotas menores que esse valor (DMV), $\mu \mathrm{m}$; e

$\mathrm{D}_{v 0,9}$ - diâmetro de gota, tal que $90 \%$ do volume do líquido pulverizado é constituído de gotas menores que esse valor, $\mu \mathrm{m}$.

Durante as aplicações, foram monitoradas as condições ambientais de temperatura, umidade relativa do ar e velocidade do vento. A temperatura variou de 18,2 a 22,7 ${ }^{\circ} \mathrm{C}$; a umidade relativa, de 63 a $79 \%$, e, a velocidade do vento, de 3,1 a $4,5 \mathrm{~km} \mathrm{~h}^{-1}$.

Inicialmente, foram testadas as pressuposições dos dados. Para verificar a homogeneidade das variâncias e a normalidade dos resíduos, foram aplicados os testes de Levene e Shapiro Wilk, respectivamente, utilizando-se o programa estatístico SPSS (versão 17.0). Para que as pressuposições fossem atendidas a 0,01 de significância, foi necessária a transformação dos dados de deposição por meio da raiz quadrada de x. Para gotas menores que 100 $\mu \mathrm{m}$, a transformação foi do tipo arco-seno da raiz quadrada de $\mathrm{x} / 100$. No caso da AR e do DMV, usaram-se os dados originais. Posteriormente, os dados foram submetidos à análise de variância e as médias foram comparadas, entre si, pelo teste de Tukey e, com a testemunha, pelo teste de Dunnett, a 0,05 de significância. Para o estudo do efeito da pressão, foi empregada análise de regressão. Determinaram-se o coeficiente de determinação e a significância dos modelos.

\section{RESULTADOS E DISCUSSÃO}

Na Tabela 2, têm-se os dados de DMV das aplicações realizadas. Eles auxiliam a compreensão dos resultados de deposição na cultura da soja, que está associada, dentre outros fatores, ao espectro de gotas. Notase que as interações entre ponta de pulverização e pres- são e entre o fatorial e a testemunha foram significativas. A ponta TVI gerou gotas de maior tamanho em todas as pressões, diferenciando-se da ponta ATR e da ponta API por ter maior DMV (acima de $420 \mu \mathrm{m}$ ). A ponta ATR também se diferenciou da ponta API, apresentando sempre menor DMV (abaixo de $130 \mu \mathrm{m}$ ). Procedeu-se à análise de regressão da pressão na interação (Figura 1). Como esperado, o incremento da pressão levou à redução do tamanho de gotas, mas este fato foi mais pronunciado na ponta de jato cônico com indução de ar, conforme pode ser visto pela inclinação das retas. Com a ponta ATR, o aumento de $1.000 \mathrm{kPa}$ levou a uma redução do DMV de apenas $57 \mu \mathrm{m}$, enquanto, com a ponta TVI, a redução foi de $166 \mu \mathrm{m}$.

Pequenas variações do tamanho das gotas provenientes de pontas de jato cônico vazio com a variação da pressão do líquido também foram constatadas por Cunha

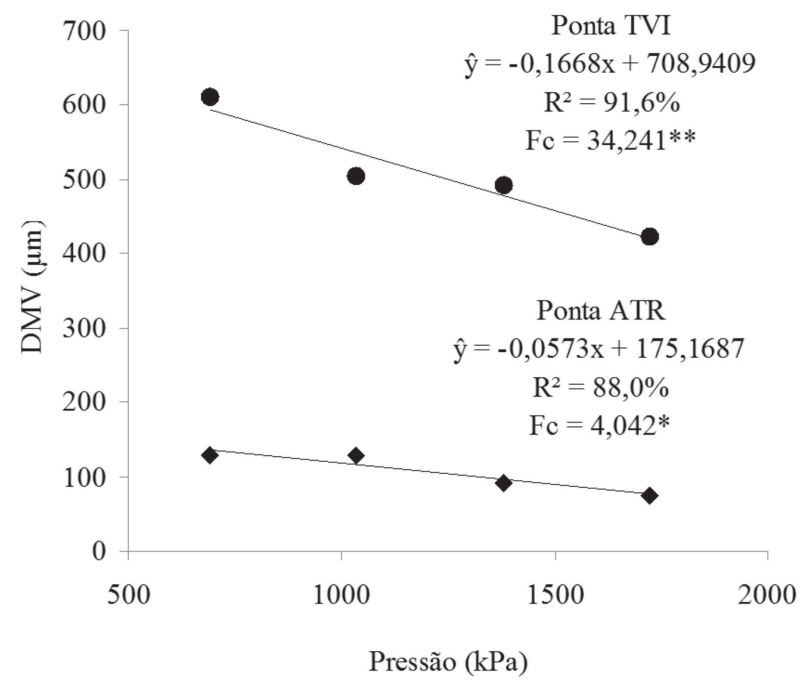

Figura 1: Regressões para diâmetro da mediana volumétrica $(\mu \mathrm{m})$ das pulverizações, em função da pressão de trabalho em pontas de jato cônico com (TVI) e sem indução de ar (ATR).

Tabela 2: Diâmetro da mediana volumétrica $(\mu \mathrm{m})$, obtido em papel hidrossensível, após as aplicações na cultura da soja, com diferentes pontas de pulverização e pressões de trabalho

\begin{tabular}{|c|c|c|c|}
\hline \multirow{2}{*}{ Pressão (kPa) } & \multicolumn{2}{|c|}{ Ponta de pulverização } & \multirow{2}{*}{ Média } \\
\hline & ATR & TVI & \\
\hline & \multicolumn{2}{|c|}{ API $(448 \mathrm{kPa})=225,05^{2}$} & \\
\hline 689 & $128,24 \mathrm{~b}^{1+}$ & $610,71 \mathrm{a}^{+}$ & 369,48 \\
\hline 1034 & $129,52 \mathrm{~b}^{+}$ & $504,44 \mathrm{a}^{+}$ & 316,98 \\
\hline 1379 & $91,26 \mathrm{~b}^{+}$ & $492,89 \mathrm{a}^{+}$ & 292,07 \\
\hline 1724 & $75,09 \mathrm{~b}^{+}$ & $422,75 \mathrm{a}^{+}$ & 248,92 \\
\hline Média & 106,03 & 507,70 & \\
\hline
\end{tabular}

\footnotetext{
${ }^{1}$ Médias seguidas por letras distintas nas linhas diferem entre si pelo teste de Tukey a 0,05 de significância; ${ }^{2}$ Médias seguidas por ${ }^{+}$diferem do tratamento adicional (ponta API a $448 \mathrm{kPa}$ ) pelo teste de Dunnett a 0,05 de significância; ${ }^{3} \mathrm{~F}_{\text {ponta }}, \mathrm{F}_{\text {pressão }}, \mathrm{F}_{\text {int }}$ e $\mathrm{F}_{\text {fatxtest }}:$ valores da estatística F para os fatores ponta, pressão, interação ponta e pressão e interação fatorial e testemunha, respectivamente. **significativo a 0,01 ; *significativo a 0,05 ; ${ }^{\text {ns }}$ não significativo.
} 
\& Silva (2007). Essas pontas apresentam faixa operacional de pressão maior. Portanto, para obter variações do tamanho das gotas, deve-se aumentar muito a pressão, o que nem sempre é desejável, em virtude do desgaste do equipamento.

Na Tabela 3, tem-se a AR das gotas geradas. Nota-se que apenas a interação entre ponta e pressão não foi significativa. A ponta de jato cônico vazio gerou gotas mais uniformes do que o mesmo modelo com indução de ar. Como a medição das gotas foi feita de forma indireta, por meio dos papéis sensíveis, ela sofre maior influência do impacto das gotas com inclusão de ar no papel. Quanto mais uniforme o tamanho de gotas, mais técnica é considerada a aplicação.

A ponta TVI não se diferenciou da ponta API, mas a ponta ATR apresentou melhor desempenho nesse quesito, com exceção do observado com a pressão de $689 \mathrm{kPa}$. Tendo em vista que o fator pressão foi significativo, procedeu-se à análise de regressão; contudo, o modelo linear não foi significativo a 0,05 de significância (Figura 2) e, por isso, a linha de tendência não foi mostrada. Consideraram-se as médias das duas pontas, visto que a interação entre ponta e pressão não foi significativa.

Nuyttens et al. (2007), avaliando a amplitude relativa para diferentes combinações de pressões e pontas de pulverização, concluíram que a variação também não foi elevada, situando-se os valores entre 0,7 e 1,3.

A percentagem do volume pulverizado, composto por gotas com diâmetro inferior a $100 \mu \mathrm{m}$, apresentada na Tabela 4 , fornece um indicativo do risco de deriva e está relacionada com o DMV. A ponta TVI, por proporcionar DMV sempre superior, também forneceu menor volume de gotas finas. A ponta ATR diferenciou-se, em todas as pressões, da ponta API.

A interação entre ponta e pressão foi significativa; então, procedeu-se à análise de regressão para pressão
(Figura 3). O incremento da pressão levou a um aumento mais pronunciado das gotas com diâmetro inferior a 100 $\mu \mathrm{m}$, com a ponta ATR, do que com a ponta TVI, sendo que, para cada aumento de $100 \mathrm{kPa}$, espera-se um acréscimo de 6,1 e $0,7 \%$, respectivamente. Isso deve ser levado em consideração, em situações em que exista risco elevado de deriva, de forma a evitar possíveis perdas para áreas não alvos.

Com relação ao estudo de deposição do traçador na cultura da soja, observa-se, nas Tabelas 5 e 6, que não houve interação significativa entre a pressão de trabalho e as pontas de pulverização, indicando que esses dois fatores apresentam uma relação de não dependência. A ponta ATR proporcionou maior deposição do que a ponta TVI. Nas folhas superiores, a diferença de deposição, considerada significativa, foi de aproximadamente $0,75 \mu \mathrm{g}$ $\mathrm{cm}^{-2}$, enquanto, nas folhas inferiores, foi de $0,22 \mu \mathrm{g} \mathrm{cm}^{-2}$.

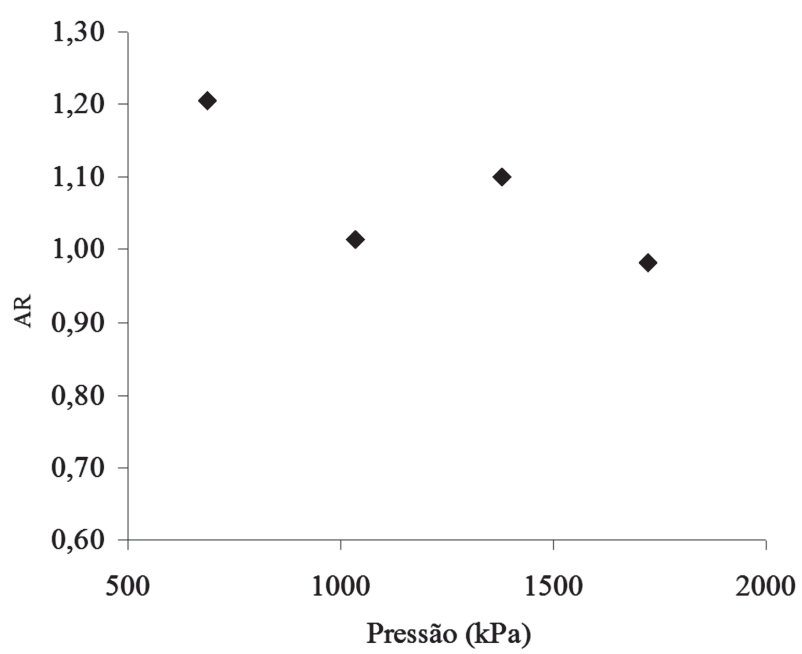

Figura 2: Amplitude relativa das pulverizações, em função da pressão de trabalho, para as médias das pontas de jato cônico com e sem indução de ar.

Tabela 3: Amplitude relativa do tamanho de gotas, obtida em papel hidrossensível, após as aplicações na cultura da soja com diferentes pontas de pulverização e pressões de trabalho

\begin{tabular}{|c|c|c|c|}
\hline \multirow{2}{*}{ Pressão (kPa) } & \multicolumn{2}{|c|}{ Ponta de pulverização } & \multirow{2}{*}{ Média } \\
\hline & ATR & TVI & \\
\hline & \multicolumn{2}{|c|}{ API $(448 \mathrm{kPa})=1,252^{2}$} & \\
\hline 689 & 1,037 & 1,373 & 1,205 \\
\hline 1034 & $0,920^{+}$ & 1,107 & 1,013 \\
\hline 1379 & $0,900^{+}$ & 1,300 & 1,100 \\
\hline 1724 & $0,770^{+}$ & 1,197 & 0,983 \\
\hline Média & $0,907 \mathrm{~b}^{1}$ & $1,244 \mathrm{a}$ & \\
\hline
\end{tabular}

${ }^{1}$ Médias seguidas por letras distintas nas linhas diferem entre si pelo teste de Tukey a 0,05 de significância; ${ }^{2}$ Médias seguidas por ${ }^{+}$diferem do tratamento adicional (ponta API a $448 \mathrm{kPa}$ ) pelo teste de Dunnett a 0,05 de significância; ${ }^{3} \mathrm{~F}_{\text {ponta }}, \mathrm{F}_{\text {pressão }}, \mathrm{F}_{\text {int }}$ e $\mathrm{F}_{\text {fatxtest }}:$ valores da estatística

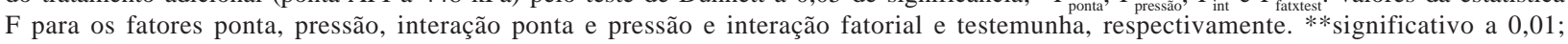
*significativo a 0,$05 ;{ }^{\text {ns }}$ não significativo. 
Tabela 4: Percentagem do volume pulverizado composto por gotas com diâmetro inferior a 100 um, obtida em papel hidrossensível, após as aplicações na cultura da soja com diferentes pontas de pulverização e pressões de trabalho

\begin{tabular}{|c|c|c|c|}
\hline \multirow{2}{*}{ Pressão (kPa) } & \multicolumn{2}{|c|}{ Ponta de pulverização } & \multirow{2}{*}{ Média } \\
\hline & ATR & TVI & \\
\hline & \multicolumn{2}{|c|}{$\operatorname{API}(448 \mathrm{kPa})=10,42^{2}$} & \\
\hline 689 & $24,21 \mathrm{a}^{+}$ & $1,27 \mathrm{~b}$ & 12,74 \\
\hline 1034 & $30,55 \mathrm{a}^{+}$ & $3,58 \mathrm{~b}$ & 17,06 \\
\hline 1379 & $54,38 \mathrm{a}^{+}$ & $4,75 \mathrm{~b}$ & 29,56 \\
\hline 1724 & $86,53 \mathrm{a}^{+}$ & $9,13 \mathrm{~b}$ & 47,83 \\
\hline Média & 48,92 & 4,68 & \\
\hline
\end{tabular}

${ }^{1}$ Médias seguidas por letras distintas nas linhas diferem entre si pelo teste de Tukey a 0,05 de significância; ${ }^{2}$ Médias seguidas por ${ }^{+}$diferem do tratamento adicional (ponta API a $448 \mathrm{kPa}$ ) pelo teste de Dunnett a 0,05 de significância; ${ }^{3} \mathrm{~F}_{\text {ponta }}, \mathrm{F}_{\text {pressãa }}, \mathrm{F}_{\text {int }}$ e $\mathrm{F}_{\text {fatxtest }}$ : valores da estatística F para os fatores ponta, pressão, interação ponta e pressão e interação fatorial e testemunha, respectivamente. ${ }^{* *}$ significativo a 0,01 ; *significativo a 0,05 ; ${ }^{\text {ns }}$ ño significativo.

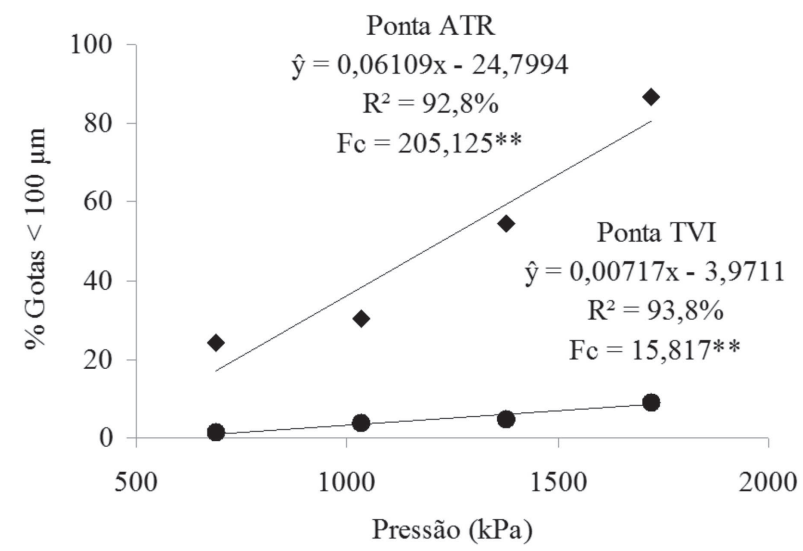

Figura 3: Curvas de regressão para percentagem do volume pulverizado composto por gotas com diâmetro inferior a 100 $\mu \mathrm{m}$, em função da pressão de trabalho, com pontas de jato cônico com (TVI) e sem indução de ar (ATR).

A ponta API, trabalhando na pressão de $448 \mathrm{kPa}$, resultou nas mesmas quantidades de traçador aplicadas pelas pontas ATR e TVI, em quaisquer pressões, visto que a interação entre o fatorial e a testemunha não foi significativa.

Por essa razão, a utilização da ponta API em vez das pontas ATR e TVI torna-se interessante, pois a API levou a deposições semelhantes do traçador, trabalhando em pressões mais baixas, gerando assim menor exigência de potência do pulverizador e, por consequência, menor desgaste do equipamento. Outro fator importante é que as pontas de pulverização de jato plano promovem uniformidade de distribuição volumétrica superior à das pontas de jato cônico (Cunha et al., 2010).

A maior deposição promovida pela ponta ATR possivelmente está associada à geração de gotas de menor tamanho. Embora mais sujeitas à deriva, as gotas finas apresentam capacidade de penetração superior no dossel das plantas. Nascimento et al. (2009), estudando o con- trole de ferrugem asiática da soja, promovido por diferentes pontas de pulverização, apontaram a eficiência de penetração de gotas finas, demonstrada pelo menor número de urédias no terço inferior da cultura, após as aplicações de fungicida. Contudo, Farinha et al. (2009), estudando a deposição de calda em pulverização terrestre, com várias pontas, em cultivares de soja no estádio $\mathrm{R} 1$, não encontraram bom desempenho, em relação à deposição de calda na parte basal, com o emprego de gotas finas, em ponta de jato cônico TX6, com volume de calda de $150 \mathrm{~L} \mathrm{ha}^{-1}$.

Neste estudo, as condições climáticas não eram favoráveis à deriva, o que pode ter auxiliado no bom resultado das gotas finas. Resultados diferentes poderiam ter ocorrido em condições de vento mais acentuadas. Por isso, não se deve generalizar a recomendação de gotas finas, visto a problemática da deriva.

Dois itens importantes a serem considerados na recomendação de pontas mais adequadas são o porte e o enfolhamento da cultura. Ao se analisar a deposição no dossel inferior, em plantas muito enfolhadas, percebe-se que a pulverização hidráulica convencional, independentemente da ponta, em geral, não é capaz de promover elevada cobertura.

A utilização das diferentes pressões de trabalho, empregadas na aplicação, promoveu diferenças quanto à deposição de calda nas folhas inferiores da soja. Nas folhas superiores, o teste F, relativo ao fator pressão, não foi significativo. Por isso, procedeu-se à análise de regressão e à verificação da significância do modelo apenas para a deposição na parte inferior. Nessa análise, o estudo foi realizado para os valores médios das pontas ATR e TVI, visto que a interação entre ponta e pressão não foi significativa. Na parte superior do dossel, a barreira imposta à passagem do jato pulverizado é menor e, por isso, é esperada menor influência da pressão. 
Tabela 5: Depósito de traçador $\left(\mu \mathrm{g} \mathrm{cm}^{-2}\right)$ nas folhas superiores da cultura da soja, após as aplicações, com diferentes pontas de pulverização e pressões de trabalho

\begin{tabular}{|c|c|c|c|}
\hline \multirow{2}{*}{ Pressão (kPa) } & \multicolumn{2}{|c|}{ Ponta de pulverização } & \multirow{2}{*}{ Média } \\
\hline & ATR & TVI & \\
\hline \multicolumn{4}{|c|}{ API $(448 \mathrm{kPa})=1,4246^{2}$} \\
\hline 689 & 2,6718 & 1,2131 & 1,9424 \\
\hline 1034 & 1,7342 & 1,1431 & 1,4387 \\
\hline 1379 & 1,5636 & 0,7700 & 1,1668 \\
\hline 1724 & 1,0322 & 0,8700 & 0,9511 \\
\hline Média & $1,7504 \mathrm{a}^{1}$ & $0,9991 \mathrm{~b}$ & \\
\hline
\end{tabular}

${ }^{1}$ Médias seguidas por letras distintas diferem entre si pelo teste de Tukey a 0,05 de significância; ${ }^{2}$ Não foi aplicado teste de Dunnett, tendo em vista a não significância da interação fatorial e testemunha; ${ }^{3} \mathrm{~F}_{\text {ponta }}, \mathrm{F}_{\text {pressão }}, \mathrm{F}_{\text {int }}$ e $\mathrm{F}_{\text {fatxtest }}$ : valores da estatística $\mathrm{F}$ para os fatores ponta, pressão, interação ponta e pressão e interação fatorial e testemunha, respectivamente. ${ }^{* *}$ *significativo a 0,01 ; * ${ }^{*}$ significativo a 0,05 ; ${ }^{\text {ns }}$ não significativo.

Tabela 6: Depósito de traçador $\left(\mu \mathrm{g} \mathrm{cm}^{-2}\right)$ nas folhas inferiores da cultura da soja, após as aplicações com diferentes pontas de pulverização e pressões de trabalho

\begin{tabular}{|c|c|c|c|}
\hline \multirow{2}{*}{ Pressão (kPa) } & \multicolumn{2}{|c|}{ Ponta de pulverização } & \multirow{2}{*}{ Média } \\
\hline & ATR & TVI & \\
\hline & \multicolumn{2}{|c|}{ API $(448 \mathrm{kPa})=0,5170^{2}$} & \\
\hline 689 & 0,6382 & 0,3558 & 0,4970 \\
\hline 1034 & 0,5923 & 0,3448 & 0,4685 \\
\hline 1379 & 0,5015 & 0,2532 & 0,3773 \\
\hline 1724 & 0,2718 & 0,1491 & 0,2104 \\
\hline Média & $0,5009 a^{1}$ & $0,2757 \mathrm{~b}$ & \\
\hline
\end{tabular}

${ }^{1}$ Médias seguidas por letras distintas diferem entre si pelo teste de Tukey a 0,05 de significância; ${ }^{2}$ Não foi aplicado teste de Dunnett, tendo em vista a não significância da interação fatorial e testemunha; ${ }^{3} \mathrm{~F}_{\text {ponta }}, \mathrm{F}_{\text {pressão }}, \mathrm{F}_{\text {int }}$ e $\mathrm{F}_{\text {fatxtest }}$ : valores da estatística $\mathrm{F}$ para os fatores ponta, pressão, interação ponta e pressão e interação fatorial e testemunha, respectivamente. ***ignificativo a 0,01 ; * ${ }^{*}$ significativo a 0,05 ; ${ }^{\text {ns }}$ não significativo.

Na Figura 4, é possível observar que a deposição do traçador nas folhas inferiores diminuiu com o aumento da pressão de trabalho. Entretanto, para as folhas superiores, a variação da pressão de trabalho não acarretou diferenças quanto à deposição do traçador (Tabela 5). Com o aumento de $1.000 \mathrm{kPa}$ na pressão, espera-se que ocorra uma diminuição de $0,28 \mu \mathrm{g} \mathrm{cm}^{-2}$ do traçador nas folhas inferiores. Isso pode ter sido causado pelo fato de que o incremento da pressão leva ao aumento do ângulo pulverizado pela ponta e, com isto, a uma diminuição da componente vertical, que auxilia na penetração do jato. Por outro lado, pode ter ocorrido também perda para o solo, nas maiores pressões, contribuindo para o resultado apresentado. Di Prinzio et al. (2010), analisando o efeito da pressão na deposição de calda no dossel de culturas arbóreas, também verificaram diminuição da deposição com o aumento da pressão.

Viana et al. (2008), estudando a cobertura de gotas no dossel de soja por diferentes pontas e pressões, verificaram comportamento diferenciado da pressão, em função da ponta empregada; em alguns casos ocorreu aumento e, em outros, decréscimo das deposições. Os autores concluíram que se deve dar preferência às menores pressões, o que vem a corroborar as conclusões deste estudo.

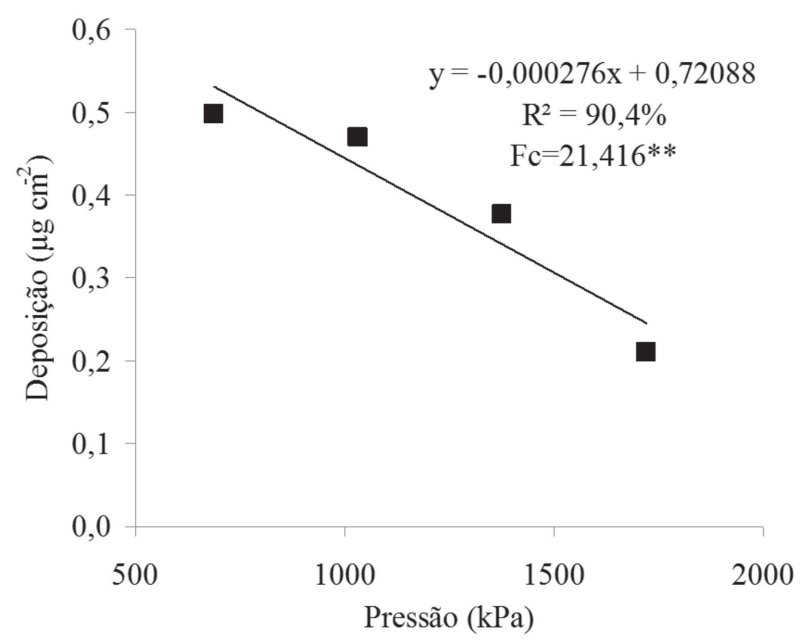

Figura 4: Curva de regressão para quantidade de traçador depositado nas folhas inferiores de soja, em função do aumento da pressão de trabalho. 


\section{CONCLUSÕES}

A ponta de jato cônico vazio, que gerou gotas de menor tamanho e mais uniformes, resultou em maior deposição de calda, tanto nas folhas superiores quanto nas folhas inferiores das plantas de soja, em comparação com a ponta de jato cônico vazio com indução de ar. O aumento da pressão de trabalho acarretou diminuição da deposição do traçador nas folhas inferiores, independentemente da ponta de pulverização, considerando-se um mesmo volume de calda. Nas folhas superiores, a pressão não influenciou a deposição do traçador. A deposição gerada pelo tratamento testemunha (ponta de jato plano a $448 \mathrm{kPa}$ ) não diferiu das geradas pelos demais tipos de pontas.

\section{REFERÊNCIAS}

Alves GS, Cunha JPAR \& Palladini LA (2014) Seleção de traçadores para estudo de eficiência das aplicações de produtos fitossanitários. Planta Daninha, 32:1-7.

Balardin RS, Navarini L \& Dallagnol LJ (2005) Epidemiologia da ferrugem da soja. In: Juliatti FC, Polizel AC \& Hamawaki OT (Eds.) Workshop Brasileiro sobre a Ferrugem Asiática. Uberlândia, EDUFU. p.39-50.

Cunha JPAR, Moura EAC, Silva Júnior JL, Zago FA \& Juliatti FC (2008) Efeito de pontas de pulverização no controle químico da ferrugem da soja. Engenharia Agrícola, 28:283-291.

Cunha JPAR, Silva RAM \& Olivet JJ (2011) Nozzle and spray volume evaluation on soybean (Glycine max (L.) Merrill) fungicide application. Revista de la Facultad de Agronomía, 28:344-359.

Cunha JPAR \& Silva RAM (2007) Uniformidade de distribuição volumétrica de pontas de pulverização em função da pressão de trabalho e altura da barra. Bioscience Journal, 26:52-58.

Cunha JPAR, Teixeira MM \& Fernandes HC (2010) Avaliação do espectro de gotas de pontas de pulverização hidráulicas utilizando a técnica da difração do raio laser. Engenharia Agrícola, 27:10-15

Di Prinzio A, Behmer S, Magdalena J \& Chersicla G (2010) Effect of pressure on the quality of pesticide application in orchards. Chilean Journal of Agricultural Research, 70:674-678.

Farinha JV, Martins D, Costa NV \& Domingos VD (2009) Deposição da calda de pulverização em cultivares de soja no estádio R1. Ciência Rural, 39:1738-1744.

Ferreira MC, Leite GJ \& Lasmar O (2013) Cobertura e depósito de calda fitossanitária em plantas de café pulverizadas com equipamentos original e adaptado para plantas altas. Bioscience Journal, 29:1539-1548.

Gallo D, Nakano O, Neto SS, Carvalho RPL, Batista GC, Filho EB, Parra JRP, Zucchi RA, Alves SB, Vendramim JD, Marchini LC, Lopes JRS \& Omoto C (2002) Entomologia agrícola. Piracicaba, FEALQ. 920p.

Godoy CV, Flausino AL, Santos LCM \& Del Ponte EM (2009) Eficiência do controle da ferrugem asiática da soja em função do momento de aplicação sob condições de epidemia em Londrina, PR. Tropical Plant Pathology 34:56-61.

Halley SS, Van Ee G, Hofman V, Panigrahi S \& Gu H (2008) Fungicide deposition measurement by spray volume, drop size and sprayer system in cereal grains. Applied Engineering in Agriculture, 24:15-21.
Nascimento JM, Souza CMA, Gavassoni WL, Bacchi LM \& Fengler GW (2009) Controle de ferrugem asiática da soja utilizando-se diferentes pontas de pulverização em Maracaju-MS. Ciencias Técnicas Agropecuarias, 18:1-6.

Nuyttens D, De Schampheleire M, Steurbaut W, Baetens K, Verboven P, Nicolai B, Ramon H \& Sonck B (2006) Experimental study of factors influencing the risk of drift from field sprayers, Part 2. Aspects of Applied Biology, 77:331-339.

Nuyttens D, Baetens K, De Schampheleire M \& Sonck B (2007) Effect of nozzle type, size and pressure on spray droplet characteristics. Biosystems Engineering, 97:333-345.

Ozkan HE, Zhu H, Derksen RC, Guler H \& Krause CR (2006) Evaluation of various spraying equipment for effective application of fungicides to control Asian soybean rust. Aspects of Applied Biology, 77:423-431.

Scramin S, Chaim A, Pessoa MCPY, Ferracini VL, Pavan LA \& Alvarenga N (2002) Avaliação de bicos de pulverização de agrotóxicos na cultura do algodão. Pesticidas: Revista de Ecotoxicologia e Meio Ambiente, 12:43-50.

Viana RG, Ferreira LR, Teixeira MM, Cecon PR \& Souza GVR (2008) Deposição de gotas no dossel da soja por diferentes pontas de pulverização hidráulica e pressões de trabalho. Engenharia na Agricultura, 16:428-435.

Viana RG, Ferreira LR, Rosell JR, Solanelles F, Planas S, Machado MS \& Machado AFL (2009) Deposición transversal de líquido de las boquillas de doble abanico TTJ60-11004 y TTJ60-11002 en distintas condiciones operacionales. Planta Daninha, 27:397403 . 